\title{
The Effect of Different Closed Suction Catheter Designs and pMDI Adapters on Aerosol Delivery in Simulated Adult Mechanical Ventilation With and Without Exhaled Humidity
}

\author{
Jacqueline P Williams RRT, Arzu Ari PhD RRT PT CPFT FAARC, \\ Ramalingam Shanmugam PhD, and James B Fink PhD RRT FAARC
}

\begin{abstract}
BACKGROUND: Closed suction catheters are commonly used with pressurized metered-dose inhalers (pMDIs) in ventilator-dependent patients receiving bronchodilator therapy. Although heated/humidified circuits result in a decrease in drug delivery, no studies have investigated the impact of a closed suction catheter with a pMDI on aerosol delivery during mechanical ventilation. We sought to quantify aerosol delivery with a variety of closed suction catheters and pMDI adapters in a simulated ventilator-dependent adult lung model with and without exhaled humidity. METHODS: A ventilator (tidal volume $450 \mathrm{~mL}$, PEEP $5 \mathrm{~cm} \mathrm{H} \mathrm{H}_{2} \mathrm{O}$, breathing frequency 15 breaths/min, peak flow $60 \mathrm{~L} / \mathrm{min}$, and bias flow $2 \mathrm{~L} / \mathrm{min}$ ) was attached to 3 closed suction catheter designs (T-piece, double swivel elbow, and a multi-access port) with pMDI adapters (small- and large-unidirectional adapters, a bidirectional adapter, and a built-in port) connected to an endotracheal tube (ETT) with a collecting filter and a passive test lung. To simulate exhaled humidity, a heated humidifier was placed between the collection filter and the distal tip of the ETT, set at $36^{\circ} \mathrm{C}$. Experiments without exhaled humidity were performed with no heat and humidification. For each test, 4 puffs of albuterol sulfate $(432 \mu \mathrm{g})$ were administered. The drug was eluted from the collecting filter and analyzed via spectrophotometer $(276 \mathrm{~nm})$. Each experiment was run 3 times. RESULTS: Delivery efficiency of the bidirectional adapter was greatest compared to other adapters tested in this study $(P=.01)$. Aerosol deposition obtained from the combination of the T-piece closed suction catheter and the bidirectional adapter was more than that from the multi-access port $(P=.42)$ and double swivel closed suction catheter $(P=.27)$. Drug delivery without exhaled humidity exceeded values with exhaled humidity by $20-90 \%$ using the small unidirectional, large unidirectional, and bidirectional adapters ( $P=.01, P=.02$ and $P=.02$, respectively). CONCLUSIONS: Closed suction catheter, pMDI spacer/ adapters, and exhalation conditions have an impact on drug delivery during simulated adult mechanical ventilation. Aerosol delivery without exhaled humidity appears to report unrealistically high values in comparison to the more accurate values with simulated exhalation humidity. Key words: aerosol; airway clearance; mechanical ventilation; closed suction catheters; metered dose inhalers; pMDI adapters; drug delivery. [Respir Care 2018;63(9):1154-1161. ( 2018 Daedalus Enterprises]
\end{abstract}

\section{Introduction}

Endotracheal suctioning is one of the most commonly practiced invasive bedside procedures performed by care provid-

Ms Williams is affiliated with the Respiratory Therapy Department, Emory University Midtown Hospital, Emory Healthcare, Atlanta, Georgia. Dr Ari is affiliated with the Department of Respiratory Care, Texas State University, San Marcos, Texas. Mr Shanmugam is affiliated with the ers to patients with artificial airways. The 2010 American Association for Respiratory Care Clinical Practice Guidelines state that aspirating pulmonary secretions from an airway to prevent its obstruction is an essential component of bronchial hygiene for mechanically ventilated patients. ${ }^{1}$ Closed system or in-line suctioning has become increasingly popular in crit-

School of Health Administration, Texas State University, San Marcos, Texas. Dr Fink is affiliated with Aerogen Pharma, San Mateo, California. 
ical care units in the United States. ${ }^{2-4}$ In this method, the closed suction catheter is enclosed within a flexible sterile plastic sleeve that allows a single catheter to be used multiple times, without having to break the ventilator circuit. Multiple designs have emerged, including multipurpose devices consisting of modular ports that allow for suctioning, bronchoscopic procedures, bronchoalveolar lavage, and drug therapy with a pressurized metered-dose inhaler (pMDI).

In addition to a closed suction catheter placed in the ventilator circuit, pMDI adapters are used to administer bronchodilator therapy. These adapters are very common because they make it easy to administer effective aerosol therapy. There are several types of commercially available adapter designs used to connect the pMDI canister to the ventilator circuit: in-line adapter, elbow adapter, collapsible large-volume cylindrical chamber spacer, non-collapsible cylindrical holding chamber, and aerosol cloud enhancer spacer. These adapters have stems extending from the pMDI from which the drug plume is emitted when the pMDI is actuated. The direction in which the pMDI plume is emitted has been described as either unidirectional, with a single outlet from the stem in 1 direction, or bidirectional, with 2 outlets exiting the stem. These designs have been reported to have a direct impact on drug delivery during mechanical ventilation. ${ }^{5-9}$ Design must be considered when selecting an adapter to deliver a reliable effective drug dose. The use of a small-volume pMDI adapter between the ventilator circuit and the patient's airway is common practice at many institutions in the United States.

After noticing a white residue accumulation in closed suction catheters, similar to that found in pMDI adapters, practitioners at our facility began to question the amount of drug delivered to ventilator-dependent patients. These observations and questions led us to investigate the impact of different closed suction catheter designs and pMDI adapters on aerosol delivery in a simulated ventilator-dependent adult lung model.

Heated/humidified circuits and heat-and-moisture exchanger (HMEs) are used to compensate for the inability of the body to heat and humidify inspired air during mechanical ventilation. Previous research has noted that heated/humidified circuits reduce aerosol drug delivery by up to $40 \%$ compared to non-humidified or dry circuits. ${ }^{6,10-12}$ However, bench studies of humidified or dry circuits may not account for the

Dr Ari discloses relationships with Bayer Pharmaceuticals, CHEST Foundation, Sunovion Pharmaceuticals, and ARC Medical. Dr Fink discloses relationships with Aerogen Pharma and Dance Biopharm. The other authors disclose no conflicts of interest.

Correspondence: Arzu Ari PhD RRT PT CPFT FAARC, Department of Respiratory Care, Texas State University, 601 University Drive, San Marcos, Texas 78666. E-mail: arzuari@ hotmail.com.

DOI: $10.4187 /$ respcare.06085

\section{QUICK LOOK}

\section{Current knowledge}

The deposition of aerosolized drugs during mechanical ventilation depends upon the designs of the pressurized metered-dose inhaler (pMDI) adapters, circuit conditions, and the presence of exhaled humidity. In health care facilities, it is common to use closed suction catheters and small-volume pMDI adapters simultaneously for aerosol drug delivery to ventilator-dependent patients.

\section{What this paper contributes to our knowledge}

The use of various closed suction catheters in a simulated mechanically ventilated adult lung model had a minimal impact on aerosol drug delivery in contrast to the pMDI adapters and simulation of exhaled conditions. The type of adapter used with pMDI affects aerosol drug delivery to ventilator-dependent patients and should be considered for optimum pulmonary drug dosage during mechanical ventilation. Simulating exhaled humidity reduced aerosol drug delivery distal to the endotracheal tube in comparison to using no exhaled humidity.

contribution of the temperature and humidity of exhaled gases on delivery of aerosol distal to the endotracheal tube (ETT). Unlike ventilated patients, who exhale heated and humidified gas close to body temperature and pressure saturated, most models use test lungs that are operated under ambient conditions, without simulation of active heating and humidification on exhalation. In vitro characterization with active heated humidity on exhalation has not been well described. These seem to be of particular relevance when aerosol is administered with HMEs.

We hypothesized that aerosol delivery would vary with closed suction catheter designs and the pMDI adapters used in ventilator-dependent patients. In addition, we expected that heated humidified exhaled humidity would reduce the quantity of drug delivered distally to the ETT. The purpose of this in vitro study was to quantify drug deposition with various pairings of closed suction catheter designs and pMDI adapters in the presence and absence of exhaled humidity in a simulated ventilator-dependent adult lung model. Figure 1 shows the scheme of the research design, including each closed suction catheter and pMDI adapter tested in this study.

\section{Methods}

\section{Closed Suction Catheters}

Three designs of adult closed suction catheters (14 Fr; Kim Vent closed suction systems, Kimberly-Clark, Roswell, Geor- 


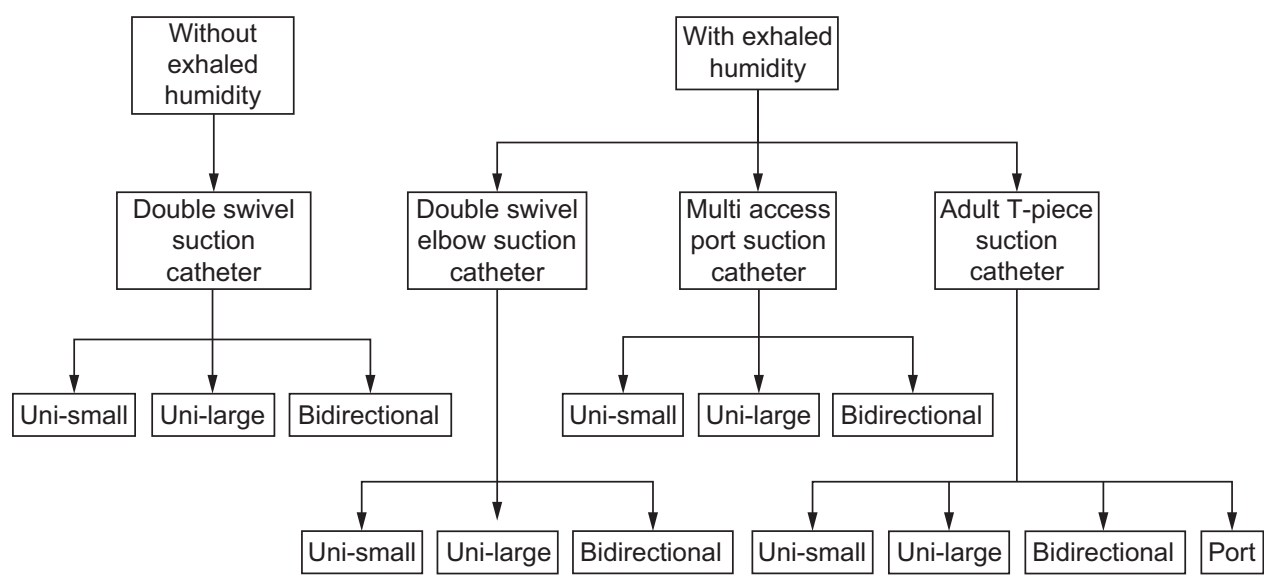

Fig. 1. Scheme of the research design, including each closed suction catheter and pMDI adapter tested in this study. Uni $=$ unidirectional.

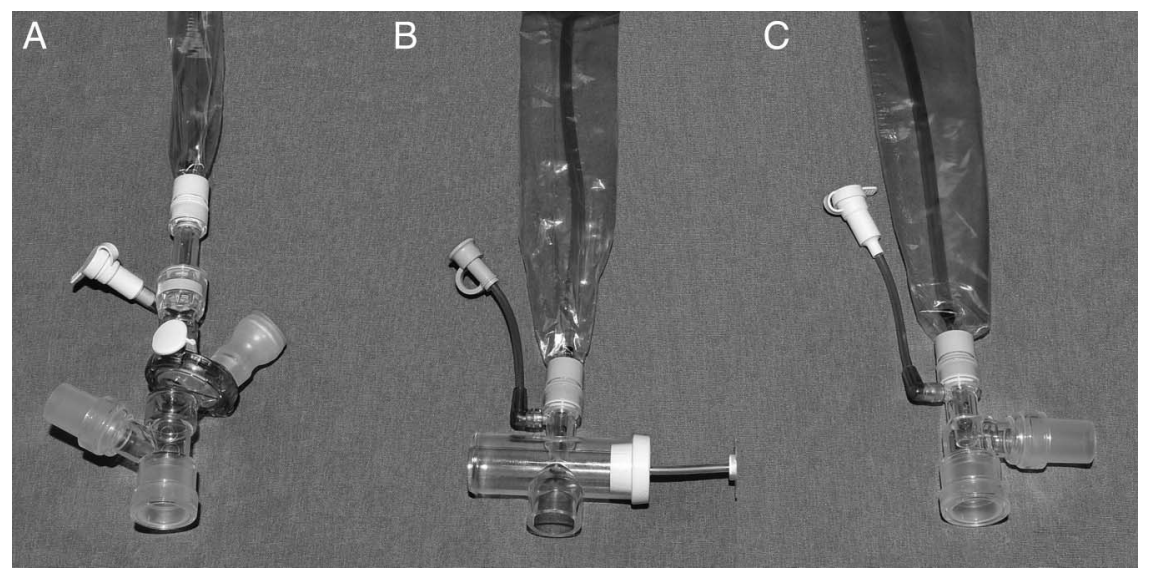

Fig. 2. Three designs of the Kimberly-Clark closed suction catheters with Ballard technology: multi-access port (A), adult T-piece (B), and double swivel elbow (C).

gia) were tested in this study (Fig. 2). The multi-access port contains multiple parts located in a rotating manifold, which connects to the ETT. This closed suction catheter attaches to the Y-piece of the ventilator circuit at a $45^{\circ}$ angle. The adult T-piece has a $90^{\circ}$ angle for gas flow exit. It is packaged with a cap that contains a pMDI port that converts the closed suction catheter into an adapter when attached. The adult double swivel elbow incorporates a standard $90^{\circ}$ elbow; the placement of an adapter between the closed suction catheter and the ETT created a $180^{\circ}$ angle.

\section{pMDI Adapters and Their Positions in the Circuit}

Four types of small-volume pMDI adapters were positioned between the HME and the ETT as shown in Figure 3 . The bidirectional flow dispenser $(22 \mathrm{~mm}$ inner diameter/22 mm outer diameter; Dual Spray Mini Spacer pMDI Adapter, Model \#1025 Thayer Medical, Tucson, Arizona) emits aerosol plumes in 2 opposing directions. The large unidirectional (uni-large) pMDI adapter (15 mm inner di- ameter/22 mm outer diameter; RTC 24 VP pMDI Adapter, Instrumentation Industries, Bethel Park, North Carolina) emits aerosol in 1 direction. The small unidirectional (unismall) pMDI adapter (15 mm inner diameter/15 mm outer diameter; RTC 15-D pMDI Adapter, Instrumentation Industries, Bethel Park, North Carolina) also emits an aerosol plume in 1 direction. The adult T-piece pMDI port attachment (Kimberly-Clark) was placed on the opposite end of the inspiratory limb of the circuit, converting the T-piece design into a small-volume reservoir. This design was tested only with the adult T-piece closed suction catheter.

\section{Lung Model}

In each experiment, a ventilator (Esprit, Philips Health Care, Andover, Massachusetts) set to simulate adult parameters with volume controlled time-cycled ventilation, breathing frequency 15 breaths $/ \mathrm{min}$, tidal volume $450 \mathrm{~mL}$, peak inspiratory flow $60 \mathrm{~L} / \mathrm{min}$, inspiratory-expiratory ratio 1:3, PEEP $5 \mathrm{~cm} \mathrm{H}_{2} \mathrm{O}$, bias flow $2 \mathrm{~L} / \mathrm{min}$, and descending 

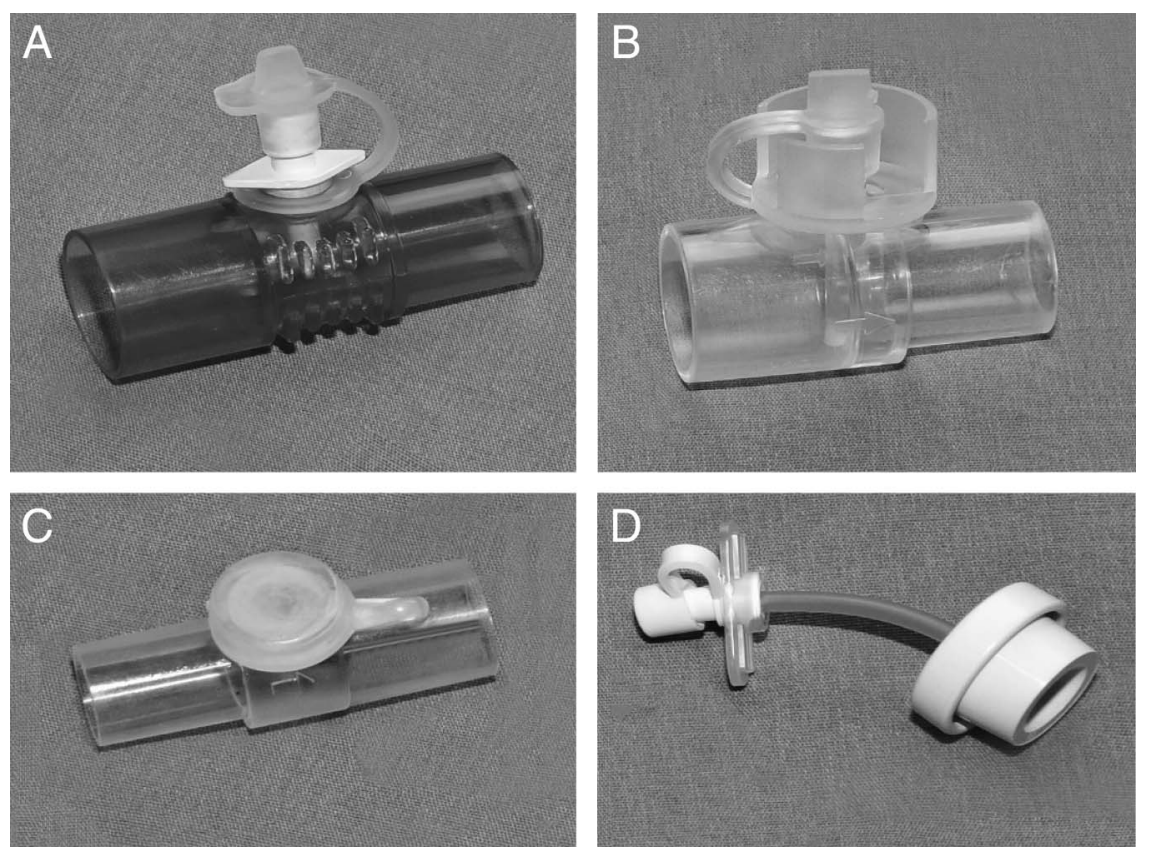

Fig. 3. Four designs of the pMDI adapters tested: (A) bidirectional, (B) large unidirectional, (C) small unidirectional, and (D) adult T-piece port.

ramp flow. A standard non-humidified ventilator circuit (Hudson RCT, Teleflex Medical, Research Triangle Park, North Carolina) was attached to a HME placed between the Y-adapter of the ventilator circuit and closed suction catheter/pMDI adapter combination that was connected to an $8 \mathrm{~mm}$ internal diameter ETT (Mallinckrodt, Covidien, Mansfield, Massachusetts). The ETT's cuff was inflated in a $15-\mathrm{mm}$ inner diameter/22 $\mathrm{mm}$ outer-diameter adapter, which was then inserted into a collecting filter (Respirgard II, 303, Vital Signs, Totowa, New Jersey), such that the ETT's tip was $1 \mathrm{~cm}$ from the filter media. The natural curve of the ETT was maintained to simulate a mechanically ventilated adult patient, with the collecting filter placed superior to the ETT to prevent drug-containing condensate from dripping on the filter. The collecting filter was connected to a passive test lung (Michigan Instruments, Grand Rapids, Michigan) set to a compliance of $0.1 \mathrm{~L} / \mathrm{cm} \mathrm{H}_{2} \mathrm{O}$ and a resistance of $5 \mathrm{~cm} \mathrm{H}_{2} \mathrm{O} / \mathrm{L}$ (Fig. 4).

As shown in Figure 4, the collecting filter was connected to $22 \mathrm{~mm}$ inner diameter corrugated tubing attached to a heated Cascade humidifier that was attached to the test lung. Prior to testing, the humidifier was allowed to equilibrate to $36 \pm 1{ }^{\circ} \mathrm{C}$ and $100 \%$ relative humidity, and this was maintained throughout the study.

\section{Data Collection}

Prior to each experiment, each pMDI (Pro Air, Teva Specialty Pharmaceuticals, Horsham, Pennsylvania) was shaken and primed with 4 actuations ( $90 \mu \mathrm{g} / \mathrm{puff}$ ), using the boot provided by the manufacturer. In each experiment, 4 puffs of albuterol sulfate were actuated at the onset of inspiration at intervals $>15 \mathrm{~s}$. The adapters were fully extended horizontally, and the pMDI was held in a vertical position during actuations. Each closed suction catheter and pMDI adapter was tested 3 times. The pMDI actuation was performed by the same tester throughout the study to minimize inter-operator variability.

\section{Data Analysis}

Drug collected on the filter was eluted with $10 \mathrm{~mL}$ 0.1-molar normal hydrochloric acid and gently agitated for 3 min. Using a spectrophotometer (Beckman Instruments, Fullerton, California), the amount of albuterol deposited in the collecting filter was determined at a wavelength of $276 \mathrm{~nm}$. The spectrophotometer was calibrated before trials using a holmium oxide filter (Beckman Instruments, Fullerton, California) to calculate wavelength accuracy. Because the data were normally distributed, descriptive statistics and 1-way analysis of variance with post hoc comparisons were used for data analysis $(P<.05)$.

\section{Results}

Table 1 summarizes the percentage of dose (mean \pm SD) and mass of albuterol deposited (mean $\pm \mathrm{SD}$ ) on the collection filter distal to the ETT for each combination of the closed suction catheter and pMDI adapter tested using an in vitro adult lung model with and without exhaled humidity. 


\section{Devices Affecting Aerosol Delivery}
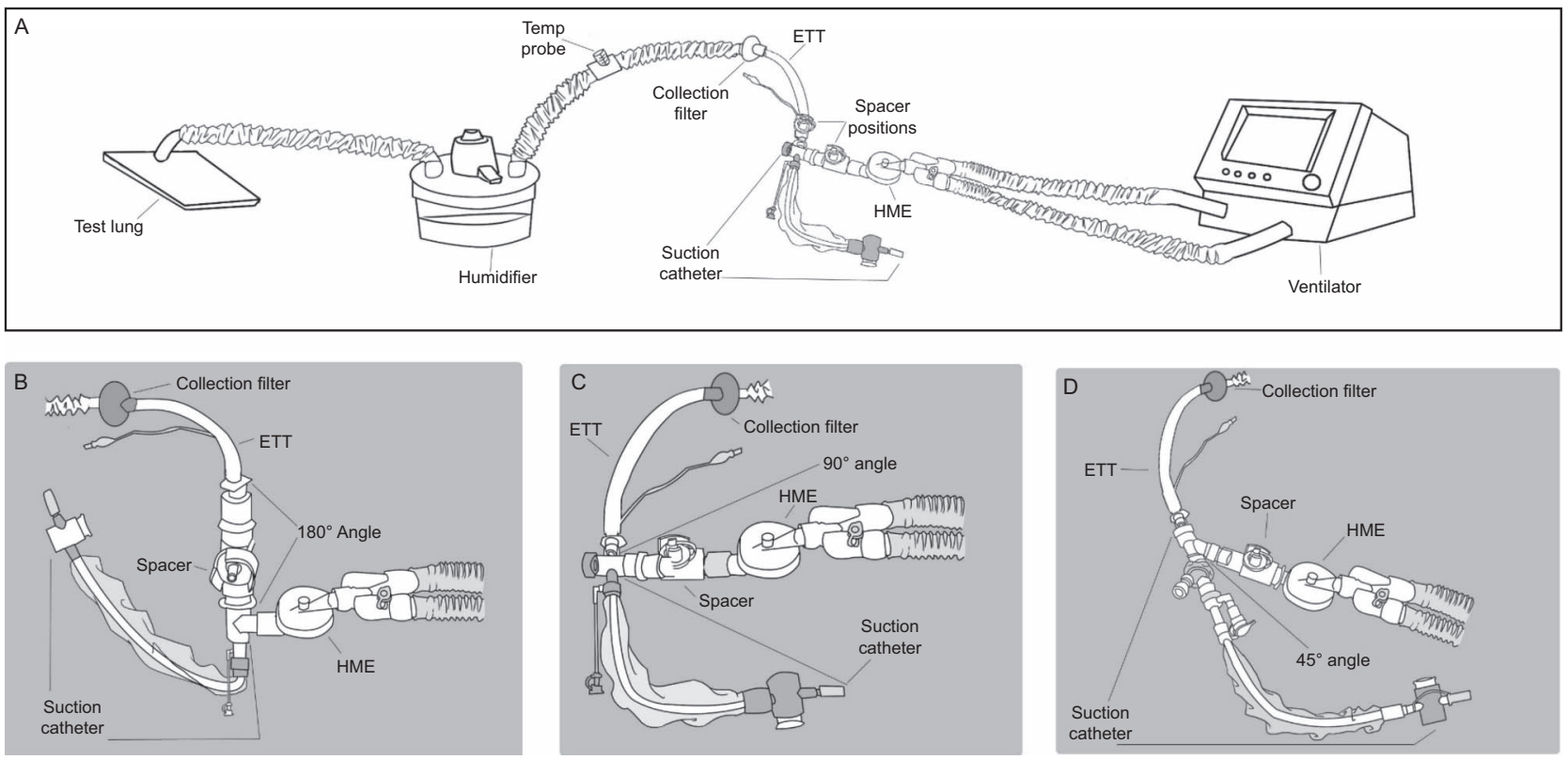

Fig. 4. (A) Experimental set-up used in this study. (B) Double swivel elbow closed suction catheter. (C) Adult T-piece closed suction catheter.

(D) Multi-access port closed suction catheter.

Table 1. Albuterol Sulfate Deposited on the Collection Filter Distal to the ETT

\begin{tabular}{|c|c|c|c|c|c|}
\hline & \multicolumn{4}{|c|}{ pMDI Spacers/Adaptors } & \multirow{2}{*}{$P$} \\
\hline & Small Unidirectional & Large Unidirectional & Bidirectional & Port & \\
\hline \multicolumn{6}{|c|}{ Without exhaled humidity } \\
\hline \multicolumn{6}{|c|}{ Double swivel } \\
\hline$\%$ of dose & $18.8 \pm 2.5$ & $24.1 \pm 5.5$ & $31.6 \pm 4.4$ & \multirow[t]{2}{*}{ NA } & .034 \\
\hline Dose, $\mu \mathrm{g}$ & $81.3 \pm 10.9$ & $103.8 \pm 23.7$ & $136.7 \pm 19.2$ & & .030 \\
\hline \multicolumn{6}{|c|}{ With exhaled humidity } \\
\hline \multicolumn{6}{|c|}{ Multi-access port } \\
\hline$\%$ of dose & $2.9 \pm 0.9$ & $7.7 \pm 1.6$ & $13.9 \pm 2.3$ & \multirow[t]{2}{*}{ NA } & .001 \\
\hline Dose, $\mu \mathrm{g}$ & $12.5 \pm 4.0$ & $33.5 \pm 6.8$ & $60.25 \pm 10.2$ & & .001 \\
\hline \multicolumn{6}{|c|}{ Double swivel } \\
\hline$\%$ of dose & $3.4 \pm 1.3$ & $7.1 \pm 1.0$ & $13.1 \pm 2.5$ & \multirow[t]{2}{*}{ NA } & .001 \\
\hline Dose, $\mu \mathrm{g}$ & $14.6 \pm 5.5$ & $30.7 \pm 4.5$ & $56.6 \pm 10.7$ & & .001 \\
\hline \multicolumn{6}{|l|}{ Adult T-piece } \\
\hline$\%$ of dose & $1.7 \pm 0.3$ & $8.7 \pm 0.4$ & $16.9 \pm 3.0$ & $1.3 \pm 0.7$ & $<.001$ \\
\hline Dose, $\mu \mathrm{g}$ & $7.4 \pm 1.7$ & $37.7 \pm 1.6$ & $73.4 \pm 13.1$ & $5.64 \pm 3.0$ & $<.001$ \\
\hline \multicolumn{6}{|c|}{$\begin{array}{l}\text { Data reflect the percentage of dose and the amount of the dose measured on the collection filter for each pairing of a closed suction catheter and pMDI spacer/adapter, with and without exhaled } \\
\text { humidity. Values are presented as mean } \pm \text { SD. } \\
\text { ETT = endotracheal tube } \\
\text { pMDI = pressurized metered-dose inhaler } \\
\text { NA = not applicable }\end{array}$} \\
\hline
\end{tabular}

\section{Drug Delivery With pMDI Adapters}

There was a statistically significant difference in drug delivery with pMDI adapters between the heated and humidified simulation and the model with dry exhalation. Regardless of the type of closed suction catheter used, the bidirectional flow dispenser had the greatest deposition, and aerosol delivery was consistently less with uni-small. Delivery efficiency of the port adapter was lowest in this simulated ventilator-dependent adult lung model.

The differences between pMDI adapters on aerosol drug delivery were most significant with the adult T-piece closed suction catheter $(P<.001)$, followed by the multi-access closed suction catheter $(P=.001)$, and then the double 
swivel closed suction catheter $(P=.001)$ without simulated exhaled humidity $(P=.034)$. Compared to other pMDI adapters, the delivery efficiency of the bidirectional flow dispenser with the adult T-piece closed suction catheter surpassed that of the uni-small $(P=<.001)$, the unilarge $(P=.002)$, and the port adapter $(P=<.001)$ followed by the performance of the uni-large adapter over the uni-small adapter $(P=.004)$ and the port adapter $(P=.003)$. No significant difference was found on aerosol delivery between the uni-small and the port adapters $(P=.99)$ with the adult T-piece closed suction catheter. When the multiaccess port closed suction catheter was used, aerosol delivery with the bidirectional flow dispenser was greater than with the uni-small adapter $(P=.001)$ and the unilarge adapter $(P=.01)$; the uni-large adapter outperformed the uni-small adapter $(P=.037)$ as well. In contrast, the double swivel closed suction catheter demonstrated no significant difference between the bidirectional flow dispenser and uni-large adapters $(P=.18)$ as well as between the uni-small and uni-large adapter $(P=.39)$. Aerosol deposition obtained with the bidirectional flow dispenser adapter was significantly greater than that with the uni-small adapter $(P=.031)$ using the double swivel closed suction catheter without exhaled humidity.

\section{Drug Delivery With Closed Suctioned Catheters}

Aerosol delivery obtained with each closed suction catheter was similar with the uni-small $(P=.16)$, uni-large $(P=.27)$, and bidirectional flow dispenser adapters $(P=.24)$. Regardless of the type of closed suction catheters used, aerosol drug delivery was consistently less with the uni-small adapter and the highest with the bidirectional flow dispenser adapter.

\section{Aerosol Deposition With and Without Exhaled Humidity}

We found that drug delivery without exhaled humidity was statistically greater than that with exhaled humidity, using the double swivel closed suction catheter paired with the uni-small adapter $(P=.01)$, the uni-large adapter $(P=.02)$, and the bidirectional flow dispenser adapter $(P=.02)$. Aerosol deposition without exhaled humidity exceeded values with exhaled humidity by $20-50 \%$.

\section{Discussion}

This is the first investigation exploring the impact of different closed suction catheter designs and pMDI adapters on aerosol drug delivery during mechanical ventilation. The findings of this study reveal that pMDI adapter designs have a greater effect on aerosol delivery than the designs of closed suction catheters. Aerosol deposition with the bidirectional flow dispenser adapter was $90 \%$ greater than that with the uni-small adapter, and $40 \%$ more than that with the uni-large adapter. In contrast, aerosol deposition with the closed suction catheter port adapter was negligible despite the use of the catheter's reservoir.

In addition, we have demonstrated that exhaled conditions of heat and humidity have a direct impact on aerosol drug delivery during mechanical ventilation. In general, experiments without exhaled humidity overestimated aerosol delivery 3- to 5-fold compared to those with exhaled humidity. Previous research reported that the designs of the pMDI adapters greatly influence aerosol drug delivery to ventilator-dependent patients. ${ }^{13-19}$ The 4 adapter designs tested in this study differed in diameter size, aerosol stems, and placement on the ventilator circuit. The in-line nonreservoir adapters (ie, the uni-small, uni-large, and bidirectional flow dispenser adapters) utilize their attachment to the corrugated tubing of the vent circuit as a space to allow plume development. The uni-small adapter was less efficient than other tested devices across the range of closed suction catheters and exhalation conditions. Intuitively, one might think a device placed closer to the patient allows less drug loss and greater deposition to the lungs. However, several studies using elbow adapters directly attached to the ETT disprove this reasoning, ${ }^{18,20,21}$ and the findings of our study were consistent with the literature. Previous in vitro studies directly attached pMDI adapters to ETTs of various sizes and reported poor performance of the ETTs with smaller diameters during mechanical ventilation. ${ }^{22,23}$ All investigators reported accumulation of white powder associated with albuterol when the pMDI adapters were directly attached to the ETTs. Their findings provided an explanation for the white residue noticed in ETTs used in this study.

The impact of adapter design was characterized by Marik et $\mathrm{al}^{24}$ with an in vivo bioavailability study of albuterol, using urinary analysis to detect albuterol levels in 30 subjects with a pMDI small spacer, a pMDI port on a rightangle, and a small-volume nebulizer. After delivering the drug directly into the ETT, the in-line spacer resulted in a bioavailability of $9 \%$ in 6 subjects and levels below detection in 4 subjects compared to $38 \%$ with a pMDI spacer and to $16 \%$ with a nebulizer. The authors concluded that a right-angle pMDI port adapter should not be used to deliver bronchodilators.

Unlike the placement of the uni-small adapter, the unilarge and bidirectional flow dispenser adapters were placed upstream on the inspiratory limb. Despite sharing an identical inner diameter of $15 \mathrm{~mm}$, the uni-large adapter delivered 2-4 times more drug than the uni-small adapter. Ari et al demonstrated that optimal drug deposition was affected by the position of the spacer in the ventilator circuit. ${ }^{25}$ They placed a large-volume chamber spacer in 3 positions: between the ETT and the Y-piece, $15 \mathrm{~cm}$ from 
the Y-piece, and $15 \mathrm{~cm}$ from the ventilator. Aerosol deposition efficiency obtained with the pMDI placed between the circuit and ETT ranged from $7.6 \%$ with heated humidity to $22.1 \%$ without humidity. 25

The design of the pMDI adapter's extended stem has been shown to affect small-volume spacers, with the dual design for discharging equal parts of drug both downstream and upstream reducing losses of aerosol associated with the unidirectional stem. Rau et $\mathrm{al}^{7}$ compared bidirectional and unidirectional in-line spacers. As in our study, they reported that delivery efficiency of bidirectional inline spacers was greater than the unidirectional spacers. Rau et $\mathrm{al}^{7}$ also reported that the chamber-shaped largevolume spacer increased drug delivery by up to 6-fold compared to unidirectional and bidirectional spacers.

Although many studies reported the impact of heat and humidity on aerosol deposition, most in vitro models do not simulate the role of the lungs in adding heat and humidity to inhaled gas. This study supports the hypothesis that simulated active exhaled humidity reduces the delivered dose of albuterol in comparison to no exhaled conditions. The temperature of the exhaled gas, hygrometer readings, and visibility of condensation in the ETT suggested that high absolute humidity was exhaled by the model. ${ }^{26-29}$ Experimental conditions with exhaled humidity more accurately simulate lung and upper airway function as reflected in a bench study by Ari et al. ${ }^{29}$ The authors reported that exhaled humidity reduced aerosol deposition by $44 \%$ compared to nonheated and nonhumidified exhalation. This is consistent with the findings of this study because we also found that drug delivery without exhaled humidity exceeded aerosol deposition obtained with exhaled humidity by $20-90 \%$ regardless of the adapters tested in this study.

\section{Limitations and Future Research}

Our study used a limited set of ventilator parameters to simulate mechanical ventilation in an adult and does not represent the array of settings, ventilation modes, and device placement found in clinical practice. In addition, the study was limited to pMDI delivery of albuterol sulfate (ProAir, Teva Pharmaceuticals) and does not represent all pMDI bronchodilators, as each drug formulation may have differences in key aerosol properties. Additional studies are needed to confirm our findings in a broader range of ventilator models, breathing patterns, and circuit and ventilator configurations. Future in vivo studies are needed to establish in vitro/in vivo correlations to confirm the impact of exhaled humidity on pulmonary deposition during mechanical ventilation.

\section{Conclusions}

The combination of a closed suction catheter, pMDI adapters, and exhaled humidity conditions affect drug delivery during simulations of ventilator-dependent adults. The selection of pMDI adapter design makes a large difference in delivered dose, while the choice of closed suction catheter has a minimal impact on delivery efficiency. The experiments without exhaled humidity appear to overestimate deposition efficiency. Future studies are needed to provide more insight and a better understanding the effects of these factors on aerosol delivery to ventilatordependent patients.

\section{REFERENCES}

1. American Association for Respiratory Care. AARC clinical practice guidelines. Endotracheal suctioning of mechanically ventilated patients with artificial airways 2010. Respir Care 2010;55(6):758-764.

2. Paul-Allen J, Ostrow CL. Survey of nursing practices with closedsystem suctioning. Am J Crit Care 2000;9(1):9-17.

3. Ozden D, Gorgulu RS. Development of standard practice guidelines for open and closed system suctioning. J Clin Nurs 2012;21(9-10): 1327-1338.

4. Seckel MA. Ask the experts. Does the use of a closed suction system help to prevent ventilator-associated pneumonia? Crit Care Nurse 2008;28(1):65-66.

5. Bishop MJ, Larson RP, Buschman DL. Metered dose inhaler aerosol characteristics are affected by the endotracheal tube actuator/adapter used. Anesthesiology 1990;73(6):1263-1265.

6. Fuller H, Dolovich M, Chambers C, Newhouse M. Aerosol delivery during mechanical ventilation: a predictive in-vitro lung model. J Aerosol Med 1992;5(4):251-259.

7. Rau J, Dunlevy C, Hill R. A comparison of inline MDI actuators for delivery of a beta agonist and a corticosteroid with a mechanicallyventilated lung model. Respir Care 1998;43:705-712.

8. Ari A, Fink JB. Aerosol delivery devices for the treatment of adult patients in acute and critical care. Curr Pharm Biotechnol 2016; 17(14):1268-1277.

9. Ari A. Aerosol drug delivery in critical pulmonary care. Respir Care 2015;60(6):858-879.

10. Diot P, Morra L, Smaldone GC. Albuterol delivery in a model of mechanical ventilation. Comparison of metered-dose inhaler and nebulizer efficiency. Am J Respir Crit Care Med 1995;152(4 Pt 1):13911394.

11. Fink JB, Dhand R, Grychowski J, Fahey PJ, Tobin MJ. Reconciling in vitro and in vivo measurements of aerosol delivery from a metered-dose inhaler during mechanical ventilation and defining efficiency-enhancing factors. Am J Respir Crit Care Med 1999;159(1): 63-68.

12. Lange C, Finlay W. Overcoming the adverse effect of humidity in aerosol delivery via pressurized metered-dose inhalers during mechanical ventilation. Am J Respir Crit Care Med 2000;161(5):16141618.

13. Hiller C, Mazumder M, Wilson D, Bone R. Aerodynamic size distribution of metered-dose bronchodilator aerosols. Am Rev Respir Dis 1978;118:311.

14. Newman S. Aerosol deposition considerations in inhalation therapy. Chest 1985;88(Suppl 2):152S.

15. Sackner MA, Kim CS. Recent advances in the management of obstructive airways disease. Auxiliary MDI aerosol delivery systems. Chest 1985;88(2 Suppl):161S-170S. 


\section{Devices Affecting Aerosol Delivery}

16. Ogrodnik N, Azzi V, Sprigge E, Fiset S, Matida E. Nonuniform deposition of pressurized metered-dose aerosol in spacer devices. $\mathrm{J}$ Aerosol Med Pulmon Drug Deliv 2016;29(6):490-500.

17. Sanders M, Bruin R. A rationale for going back to the future: use of disposable spacers for pressurised metered dose inhalers. Pulmon Med 2015;176194.

18. Fuller HD, Dolovich MB, Turpie FH, Newhouse MT. Efficiency of bronchodilator aerosol delivery to the lungs from the metered dose inhaler in mechanically ventilated patients. A study comparing four different actuator devices. Chest 1994;105(1):214-218.

19. Rau J, Harwood R, Groff J. Evaluation of a reservoir device for metered-dose bronchodilator delivery to intubated adults: an in-vitro study. Chest 1992;102(3):924-930.

20. Dhand R, Tobin MJ. Bronchodilator delivery with metered-dose inhalers in mechanically-ventilated patients. Eur Respir J 1996;9(3): 585-595.

21. Robertson S, Canary CW, Orr M, Herberg P, Rutledge DN. Factors related to progression and graduation rates for $\mathrm{RN}$-to-bachelor of science in nursing programs: searching for realistic benchmarks. J Prof Nurs 2010;26(2):99-107.

22. Crogan SJ, Bishop MJ. Delivery efficiency of metered dose aerosols given via endotracheal tubes. Anesthesiology 1989;70(6):1008-1010.
23. Takaya T, Takeyama K, Takiguchi M. The efficiency of beta 2-agonist delivery through tracheal tubes with the metered-dose inhaler: an in vitro study. J Anesth 2002;16(4):284-288.

24. Marik P, Hogan J, Krikorian J. A comparison of bronchodilator therapy delivered by nebulization and metered-dose inhaler in mechanically ventilated patients. Chest 1999;115:1653-1657.

25. Ari A, Areabi H, Fink JB. Evaluation of position of aerosol device in two different ventilator circuits during mechanical ventilation. Respir Care 2010;55(7):837-844.

26. Ricard JD, Markowicz P, Djedaini K, Mier L, Coste F, Dreyfuss D. Bedside evaluation of efficient airway humidification during mechanical ventilation of the critically ill. Chest 1999;115(6):1646-1652.

27. Restrepo RD, Walsh BK. Humidification during invasive and noninvasive mechanical ventilation: 2012. Respir Care 2012;57(5):782-788.

28. Ari A, Alwadeai KS, Fink JB. Effects of heat and moisture exchangers and exhaled humidity on aerosol deposition in a simulated ventilator-dependent adult lung model. Respir Care 2017; 62(5):538-543.

29. Ari A, Harwood R, Sheard M, Alquaimi MM, Alhamad B, Fink JB. Quantifying aerosol delivery in simulated spontaneously breathing patients with tracheostomy using different humidification systems with or without exhaled humidity. Respir Care 2016; 61(5):600-606. 